\title{
Maternal-Fetal Medicine Specialists Should Manage Patients Requiring Fetal MRI of the Central Nervous System
}

l: t has been established that fetal MR imaging can provide increased sensitivity and specificity for fetal central nervous system abnormalities, ${ }^{1}$ but whether a given diagnostic test will change management should also be considered when the value of the test is assessed.

Having worked with the first fetal MR imaging program in a rural region in the central United States some years ago, I recall that the requests for fetal MR imaging ramped up in the years following its initiation: Forty-six fetal MRIs in 44 patients were performed to interrogate possible CNS abnormalities during the first 58 months of the program. Our experience in this nonacademic community setting mirrored larger studies that have since confirmed the improved accuracy of MR imaging compared with sonography. ${ }^{2}$ With fetal MR imaging as the criterion standard in this small sample, sonography was shown to be $61 \%$ accurate for ventriculomegaly, $80 \%$ accurate for callosal dysgenesis, 93\% accurate for holoprosencephaly, and 100\% accurate for encephalocele. However, only $14 \%$ of the MR imaging scans were performed in cases in which changing the sonography-based diagnosis would have affected counseling, and no management changes were observed during pregnancy in this community as a result of MR imaging findings. In contrast, a study performed at a larger American academic center reported that antenatal management changes were observed in $18.6 \%$ of cases in the early years of fetal MR imaging. ${ }^{3}$

An element of "Gizmo Idolatry" may be more likely to manifest at nonacademic medical centers. Most data on fetal MRIs have arisen from the academic setting as opposed to the nonacademic community setting, and it is likely that these epicenters of advanced pathology are more likely to see and treat advanced CNS disorders. My concern is that if fetal MR imaging use becomes more widespread without consultation with a maternal-fetal medicine specialist, the availability of the examination, rather than its potential to change medical management, will drive use.

http://dx.doi.org/10.3174/ajnr.A5894
Fetal MR imaging requires considerable resources. Technologist training, radiologists being present for supervision, and counseling by the interpreting physician all add considerable complexity to the study. Fetal MR imaging is considerably more expensive than sonography, though the actual reimbursement may not be commensurate with the amount of time and resources allocated.

In summary, the superior diagnostic quality that fetal MR imaging provides has been well-established. Increasing availability is almost always followed by increased use without necessarily adding value to the health care system, and more science may be needed to justify the cost of this examination if the result would not add management-changing information to the ultrasound result. Fetal MR imaging may be quite valuable in the hands of skilled specialists in large quaternary care centers when ultrasound suggests pathology, but a more liberal application of fetal MR imaging may not be advantageous on a cost-benefit basis. If ordering fetal MR imaging in a patient with normal findings on prenatal sonography becomes commonplace as has been suggested, ${ }^{1}$ the potential for increased cost to the health care system is great, particularly if we drift away from emphasizing high-quality sonography as an acceptable standard in fetal imaging.

\section{REFERENCES}

1. Griffiths PD, Mooney C, Bradburn M, et al. Should we perform in utero MRI on a fetus at increased risk of a brain abnormality if ultrasonography is normal or shows non-specific findings? Clin Radiol 2018;73:123-34 CrossRef Medline

2. Griffiths PD, Bradburn M, Campbell MJ, et al; MERIDIAN collaborative group. Use of MRI in the diagnosis of fetal brain abnormalities in utero (MERIDIAN): a multicentre, prospective cohort study. Lancet 2017;389:538-46 CrossRef Medline

3. Levine D, Barnes PD, Robertson RR, et al. Fast MR imaging of fetal central nervous system abnormalities. Radiology 2003;229:51-61 CrossRef Medline

4. Leff B, Finucane TE. Gizmo idolatry. JAMA 2008;299:1930-32 Medline

(1) C.M. Pfeifer

Department of Radiology University of Texas Southwestern Medical Center Dallas, Texas 